\title{
TOKEN ECONOMY APPROACH AND PHYSICAL ACTIVITY: A SHORT REPORT FOR PATIENTS WITH SCHIZOPHRENIA
}

\author{
Georgia Maggouritsa ${ }^{1 \mathrm{i}}$, \\ Dimitrios Kokaridas ${ }^{1}$, \\ Konstantinos Bonotis ${ }^{2}$ \\ ${ }^{1}$ Department of Physical Education and Sport Science, \\ University of Thessaly, \\ Greece \\ ${ }^{2}$ Department of Psychiatry, \\ Faculty of Medicine, \\ University of Thessaly, \\ Greece
}

\begin{abstract}
:
The purpose of this study is to provide a short report concerning token economy system application in psychiatry units and connect this approach with physical activity programming, as an effective way to promote psychological benefits, skills and exercise behavior of patients with schizophrenia. Conclusions: Token economy combined with physical activity can be a useful non-pharmaceutical approach that helps patients with schizophrenia to improve psychological aspects and quality of life.
\end{abstract}

Keywords: schizophrenia, token economy, exercise

\section{Behavioural treatments and token economy}

Behaviouristic treatments use the principles of conventional therapy for the treatment of mental disorders. Behavioral modification techniques are used mainly in the treatment of psychoses and include three main steps. That is, the determination of the undesirable or non-adaptive behaviour, restructuring of the environment and determination of support that maintains or increase desirable behaviors through reinforcements that link the cause with effect for the behavior voluntarily demonstrated. Desirable behaviors (target behaviors) are considered those associated with the achievement of new skills and reduce of undesirable behaviors that improve self-support capabilities and personal hygiene of the patient as well as his participation in daily activities at work, social interaction and participation in treatment (Hupp, Reitman, Northup, O'Callaghan \&

i Correspondence: email gmag@uth.gr 
LeBlanc, 2002; Comaty, Stasio \& Advokat, 2001; Kahng, Boscoe \& Byrne 2003; Reitman, Hupp, O'Callaghan, Gulley, \& Northup, 2001).

A type of behavioral therapy using a kind of exchange (token) that is given as a reward at a specified moment during the program in the occasion of positive behaviors portrayed by the patient is called "token economy system" (Comaty, et al., 2001; Kahng, et al., 2003). With this direct connection between "cause and effect", behavior changes for the better by skillful manipulation of the environment responsible for this positive change. The token economy system is actually an effective way to change behavior to acquire new skills, reduce undesirable behaviors and aggression, increase treatment compliance and improve management of psychiatric unit (LePage, DelBen, Pollard et. al., 2003).

The method has its roots in the study of Ayllon and Haughton (1962) who asked to visit a hospital where staff had difficulties to cope with patients with schizophrenia to eat on time. The effectiveness of the reward system for increasing adaptive function of patients with mental illness in psychiatric hospitals then proved in various studies (Henderson \& Scoles, 1970; Hersen, Eisler, Smith \& Agras, 1972; Nelson \& Cone, 1979; Winkler, 1971). An intensive study of 6 years showed that the use of exchangeable rewards reduced aggression and unusual behavior and increased life skills to almost typical standards (Paul \& Lentz, 1977). According to Glynn (1990) and Corrigan (1995) who investigated the advantages and limitations of token economy system approach up to mid-1990s, over 200 studies described the significant benefits of using rewards in psychiatry settings.

The success of a token economy depends on the appeal of the primary reinforcers which are the meaningful objects, privileges or activities that individuals receive in exchange for their tokens. In practice, reinforcers help the individual to regain skills and behavioral patterns and they are more effective in changing behaviors than punishment in these populations (McMonagle \& Sultana, 2000). Since severe and persistent mental disorders are associated with neuro-cognitive weakness, apathy and kinetic inertness, external rewards can help patients in active participation and retention in treatment (Smith, Hull, Goodman, et al., 1999; Silverstein, 2010). As an example, the degree of participation in a treatment program of non-hospitalized people with mental illness and substance abuse improved with the use of external rewards, having access to housing with tokens and beneficiary services for monthly nursing and housing (Tenhula, Bellack, Suarez, Lambert, \& Ford, 2003; Ho, Tsuang, Liberman et al., 1999; Lehman, Kreyenbuhl, Buchanan et al., 2004).

Although the use of exchangeable rewards was successful and its application has proven to be an effective behavioral therapy for individuals with psychotic behavior, however, its use in clinical and research structures has declined from its peak during the 1970s mainly due to financial reasons or attention given to other treatments and moral challenges (Mei-Feng, Jaw-Haw, Mei-Hsien \& Mei-Chi, 2006; Dickerson, Dickerson, Tenhula \& Green-Paden, 2005). 
In addition, rewards were used mainly for improving behaviors that are not related to participation in exercise, such as improving household skills (Jason, 1985) or academic performance (McGinnis, Friman \& Carlyon, 1999), reducing hours of TV monitoring (Wolfe, Mendes \& Factor, 1984) and criminal behavior (Christopherson, Arnold, Hill \& Quilitch, 1972), minimizing reaction time between an instruction given and its implementation (Fjellstedt \& Sulzer-Azaroff, 1973) and improving the environment of the psychiatric unit while reducing negative incidents (LePage, et al., 2003). Overall, researches using a token economy system approach in multiple settings other than exercise validated its effectiveness as a behavioural treatment in both acute and more intermediate psychiatric care (McGinnis, Friman, \& Carlyon, 1999) through application of rewards for clearly defined target behaviors (Dixon, Dickerson, Bellack et al., 2010).

\section{Physical activity and token economy system review}

However, reviewing the literature, it seems that studies conducted combining physical activity with token economy treatment is scarce. Although benefits occur only for those who consistently exercise and increase of positive exercise behavior to improve health is a key issue especially for patients with schizophrenia who seldom exercise and are less physically active mainly due to apathy and lack of motivation (Lindamer, McKibbin, Norman, et al., 2008; Stubbs, Firth, Berry et al., 2016; Beebe \& Smith, 2010), only few studies have tried to promote exercise behavior (Maggouritsa, Kokaridas, Theodorakis et al., 2014a).

Although Beebe and Smith (2010), Menza, Vreeland, Minsky et al., (2004), and Gholipour, Abolghasemi, Gholinia \& Taheri (2012), showed that motivational interventions can increase exercise behaviors achieving higher attendance rates no other recent researches has been noted to combine exercise set within a behavioral modification program that is necessary to increase positive behaviors toward exercise and minimize drop out risk. Quite clearly, physical activity interventions should incorporate not only application of exercises, but also implementation of behavior strategies to produce desirable results (Fassino, Amianto, Abbate Daga \& Leombruni, 2007; Gholipour, et al., 2012).

In this regard, only three studies examined the effect of a token economy system program combined with physical activity on improving psychological aspects of patients with schizophrenia, concerning quality of life (Kokaridas, Maggouritsa, Stoforos, et al., 2013) mood profile (Maggouritsa, Kokaridas, Theodorakis et al., 2014a) and self-esteem and body cathexis (Maggouritsa, Kokaridas, Stoforos, et al., 2014b).

These studies concerned the application of an 8 weeks exercise program at a frequency three times a week, combined with token economy behavioral treatment to 30 patients with schizophrenia assigned randomly in two groups, that is, control $(\mathrm{N}=10)$ and experiment $(\mathrm{N}=20)$. Control group participants did not attend any training session, whereas the experiment group of 20 patients was randomly separated in two groups of 
10 patients, that is, an exercise observation with tokens group (experiment group A) and an actual exercise with tokens group (experiment group B).

In each exercise session, each participant of both experimental groups $A$ and $B$ had the opportunity to receive two tokens that is, a plastic coin prior the beginning of each training session was awarded for being on time and a participation certificate as a second token at the end of the exercise session, rewarded the consistency of patients to observe (group A) or to participate (group B) the whole 45 minutes session required. Following three sessions, only the individuals who gained 6 tokens had the right to receive a more significant token as a bonus of their consistency and appropriate behavior at the end of each week. Number of smaller and bigger tokens provided throughout the program was gradually reduced without however being completely withdrawn.

As regards the effect of the exercise and token economy program, experiment group B participants felt less depressed and more energetic leading to an improved mood profile, quality of life and higher self-esteem compared to the other two groups. Moreover, participation in exercise improved their social and health skills and overall body care as a result of an improved tendency for personal hygiene.

Overall, in terms of the effect of exercise on psychological measures for patients with schizophrenia, the results were positive for those who exercised but not for those did not participate (control group) or simply observed the exercise program (group A). The fact that no changes were observed after the study for the experiment group A although receiving token economy treatment, shows the importance to participate in the exercise program to produce psychological benefits. Furthermore, since no drop-outs occurred during intervention for the individuals of both experiment groups, highlights the importance of the token economy system to motivate individuals to be a part of the exercise process. Thus, the combination of both procedures seems to produce the most desirable results.

Gorczynski, Sitch \& Faulkner (2017), in their review noted how important is the presence of multiple messengers (friends, relatives or nursing personnel) during exercise to support and encourage this population to participate without drop out occurrence. Since the application of the token economy program in the studies of Kokaridas et al., (2013) and Maggouritsa et al., (2014a, \& 2014b) resulted to no drop-outs occurred without the presence of patients' relatives or nursing personnel, highlights even further the influence of the token economy system to motivate patients with schizophrenia to exercise. This is even more important in case the administration and safety rules in psychiatry hospitals do not allow the presence of patients' relatives during therapeutic treatment, since laws that define administration in psychiatry units differ greatly among countries.

\section{Conclusions and future suggestions}

Quite clearly, physical exercise should play a more active role in mental health care (McCormick, Frey, Lee et al., 2008; Lee, Arthur \& Avis, 2008), focusing on what motivates 
or interests each individual to take part in physical activity as a very important part of their treatment (Grant, 2000) in agreement with other studies (Acil, Dogan \& Dogan, 2008; Carless \& Douglas, 2004; Duraiswamy, Thirthalli, Nagendra \& Gangadhar, 2007; Fogarty \& Happell, 2005). Future studies should explore whether the use of extrinsic rewards is necessary to set the conditions under which internal motivation can develop (Park, Gibson \& McMichael, 2006) leading to cognitive remediation in schizophrenia (Silverstein, 2010).

Overall, results of token economy system application in physical activity programming are promising as regards to improving behavior toward exercise as well as psychological aspects of participants with schizophrenia. It seems that physical activity programs of this kind could help persons to adopt more healthy attitudes as part of their everyday routine so as to promote their psychological well-being and quality of life (Holley, Crone, Tyson \& Lovell, 2011).

Since the studies of Kokaridas et al. (2013) and (Maggouritsa et al. (2014a \& 2014b) appear the first of their kind, future studies using larger samples, longer in duration physical activity programs and follow ups are needed to further validate promising results. The overall intention is to ascertain whether physical activity combined with therapeutic treatments such as the token economy approach can be a useful nonpharmaceutical approach that helps patients with schizophrenia to improve psychological aspects of everyday life.

\section{Conflicts of interest}

The authors declare that there are no conflicts of interest.

\section{About the Authors}

Georgia Maggouritsa, Permanent Teaching Staff, Department of Physical Education and Sport Science, University of Thessaly, Greece.

Dimitrios Kokaridas, Associate Professor, Department of Physical Education and Sport Science, University of Thessaly, Greece

Konstantinos Bonotis, Assistant Professor, Department of Psychiatry, Faculty of Medicine, University of Thessaly, Greece.

\section{References}

Acil A, Dogan S, Dogan O, 2008. The effects of physical exercises to mental state and quality of life in patients with schizophrenia. Journal of Psychiatric and Mental Health Nursing, 15: 808-815.

Ayllon T, Haughton E, 1962. Control of the behavior of schizophrenic patients by food. Journal of the Experimental Analysis of Behavior, 5: 343-352. 
Beebe L.H, Smith K, 2010. Feasibility of the Walk, Address, Learn and Cue (WALC) Intervention for Schizophrenia Spectrum Disorders. Archives of Psychiatric Nursing, 24: 54-62.

Carless D, Douglas K. A, 2004. A golf programme for people with severe and enduring mental health problems. Journal of Public Mental Health, 3: 26-39.

Christopherson E.R, Arnold C.M, Hill D.W, Quilitch H.R, 1972. The home point system: token reinforcement procedures for application by parents of children with behavior problems. Journal of Applied Behavior Analysis, 5: 485-497.

Comaty J.E, Stasio M, Advokat C, 2001. Analysis of outcome variables of a token economy system in a state psychiatric hospital: a program evaluation. Research in Developmental Disabilities, 22(3): 233-253.

Corrigan P.W, 1995. Use of token economy with seriously mentally ill patients: Criticisms and misconceptions. Psychiatric Services, 46: 1258-1263.

Dickerson F, Tenhula W.N, Green-Paden L.D, 2005. The token economy for schizophrenia: review of the literature and recommendations for future research. Schizophrenia Research, 75: 405-416.

Dixon L.B, Dickerson F, Bellack A.S, Bennett M, Dickinson D, Goldberg, R.W, Lehman A, Wendy N, Tenhula W.N, Calme C, Pasillas R.M, Peer J, Kreyenbuhl J, 2010. The 2009 Schizophrenia PORT Psychosocial Treatment Recommendations and Summary Statements. Schizophrenia Bulletin, 36: 48-70.

Duraiswamy G, Thirthalli J, Nagendra H. R, Gangadhar B. N, 2007. Yoga therapy as an add-on treatment in the management of patients with schizophrenia - a randomised control trial. Acta Psychiatrica Scandinavica, 116: 226-232.

Fassino S, Amianto F, Abbate Daga G, Leombruni P, 2007. Personality and psychopathology correlates of dropout in an outpatient psychiatric service. Panminerva Medica, 49: 7-15.

Fjellstedt N, Sulzer-Azaroff B, 1973. Reducing the latency of a child's responding to instructions by means of a token system. Journal of Applied Behavior Analysis, 6: 125-130.

Fogarty M, Happell B, 2005. Exploring the benefits of an exercise program for people with schizophrenia: A qualitative study. Issues in Mental Health Nursing, 26: 341-351.

Gholipour A, Abolghasemi SH, Gholinia K, Taheri S, 2012. Token Reinforcement Therapeutic Approach is More Effective than Exercise for Controlling Negative Symptoms of Schizophrenic Patients: A Randomized Controlled Trial, International Journal of Preventive Medicine, 3:466-70.

Glynn S.M, 1990. Token economy approaches for psychiatric patients: Progress and pitfalls over 25 years. Behavior Modification, 14: 383-407.

Gorczynski P F, Sitch M, Faulkner G, 2017. Examining methods, messengers and behavioural theories to disseminate physical activity information to individuals with a diagnosis of schizophrenia: a scoping review. Journal of Mental Health, 110 . 
Grant T, 2000. Physical activity and mental health - national consensus statements and guidelines for practitioners. London: Health Education Authority.

Henderson J.D, Scoles P.E, 1970. Conditioning techniques in a community-based operant environment for psychotic men. Behavior Therapy, 1: 245-251.

Hersen M, Eisler R.M, Smith B.S, Agras W.S, 1972. A token reinforcement ward for young psychiatric patients. American Journal of Psychiatry, 129: 142-233.

Ho A.P, Tsuang J.W, Liberman R.P, Wang R, Wilkins J.N, Eckman T.A, Shaner A.L, 1999. Achieving effective treatment of patients with chronic psychotic illness and comorbid substance dependence. American Journal of Psychiatry, 156: 1765-1770.

Holley J, Crone D, Tyson P, Lovell G, 2011. The effects of physical activity on psychological well-being for those with schizophrenia: A systematic review. British Journal of Clinical Psychology, 50:84-105.

Hupp S. D. A, Reitman D, Northup J, O'Callaghan P, LeBlanc M, 2002. The effects of delayed rewards, tokens, and stimulant medication on sportsmanlike behavior with ADHD-diagnosed children. Behavior Modification, 26: 148-162.

Jason L.A, 1985. Using a token-actuated timer to reduce television viewing. Journal of Applied Behavior Analysis, 18: 269-272.

Kahng S, Boscoe J, Byrne S, 2003. The use of an escape contingency and a token economy to increase food acceptance. Journal of Applied Behavior Analysis, 36: 349-353.

Kokaridas D, Maggouritsa G, Stoforos P, Patsiaouras A, Theodorakis Y, Diggelidis N, 2013. The effect of a token economy system program and physical activity on improving quality of life of patients with schizophrenia: a pilot study. American Journal of Applied Psychology, 2: 80-88.

Lee L.L, Arthur A, Avis M, 2008. Using self-efficacy theory to develop interventions that help older people overcome psychological barriers to physical activity: a discussion paper. International Journal of Nursing Studies, 45: 1690-1699.

Lehman F A, Kreyenbuhl J, Buchanan W R, Dickerson B F, Dixon B L, Goldberg R, GreenPaden D L, Tenhula N W, Boerescu D, Tek C, Sandson N, Steinwachs M D, 2004. The Schizophrenia Patient Outcomes Research Team (PORT): updated treatment recommendations 2003. Schizophrenia Bulletin, 30:193-217.

LePage J. P, DelBen K, Pollard S, McGhee M, VanHorn L, Murphy J, Lewis P, Aboraya A, Mogg N, 2003. Reducing assaults on an acute psychiatric unit using a token economy: A 2-year follow-up. Behavioral Interventions, 18: 179-190.

Lindamer, L.A., McKibbin, C., Norman, G.J., Jordan, L., Harrison, K., Abeyesinhe, S., \& Patrick, K. (2008). Assessment of physical activity in middle-aged and older adults with schizophrenia. Schizophrenia Research, 104: 294-301.

Maggouritsa G, Kokaridas D, Stoforos P, Patsiaouras A, Diggelidis N, Theodorakis' Y, 2014b. The Effect of a Physical Activity Program on Improving Body Cathexis and Self-Esteem of Patients with Schizophrenia. Inquiries in physical education and sport, 12: 40-51.

Maggouritsa G, Kokaridas D, Theodorakis Y, Patsiaouras A, Mouzas O, Dimitrakopoulos S, Diggelidis N, 2014a. The Effect of a Physical Activity Program on Improving 
Mood Profile of Patients with Schizophrenia. International Journal of Sport \& Exercise Psychology, 12: 273 -284.

McCormick B.P, Frey G, Lee C, Chun S, Gajic J, Stamatovic-Gajic B, Maksimovich M, 2008. Predicting Transitory Mood from Physical Activity Level Among People With Severe Mental Illness in Two Cultures. International Journal Social Psychiatry, 54: 527-538.

McGinnis J.C, Friman P.C, Carlyon W.D, 1999. The effect of token rewards on intrinsic motivation for doing math. Journal of Applied Behavior Analysis, 32: 375-379.

McMonagle T, Sultana A, 2000. Token economy for schizophrenia (Cochrane Review). The Cochrane Database of Systematic Reviews, 3, CD001473.

Mei-Feng L, Jaw-Haw C, Mei-Hsien C, Mei-Chi H, 2006. Significant experiences of token therapy from the perspective of psychotic patients. The Journal of Nursing Research, 14: 315-23.

Menza M, Vreeland B, Minsky S, Gara M, Radler D.R, Sakowitz M, 2004. Managing atypical antipsychotic-associated weight gain: 12-month data on a multimodal weight control program. Journal of Clinical Psychiatry, 65: 471-477.

Nelson G, Cone J.D, 1979. Multiple-baseline analysis of a token economy for psychiatric patients. Journal of Applied Behavior Analysis, 12: 255-271.

Park S, Gibson C, McMichael T, 2006. Socio-affective factors modulate working memory in schizophrenic subjects. Neuroscience, 139:373-384.

Paul G.L, Lentz R.J, 1977. Psychosocial Treatment of Chronic Mental Patients: Milieu versus Social-learning Programs. Cambridge, MA: Harvard University Press.

Reitman D, Hupp S. D. A, O'Callaghan P.M., Gulley V, Northup N, 2001. The influence of a token economy and methylphenidate on attentive and disruptive behavior during sports with ADHD-diagnosed children. Behavior Modification, 25: 305323.

Silverstein S.M, 2010. Bridging the Gap between Extrinsic and Intrinsic Motivation in the Cognitive Remediation of Schizophrenia. Schizophrenia Bulletin, 36: 949-956.

Smith T.E, Hull J.W, Goodman M, Hedayat-Harris A, Willson D.F, Israel L.M, Munich R.L, 1999. The relative influences of symptoms, insight, and neurocognition on social adjustment in schizophrenia and schizoaffective disorder. Journal of Nervous and Mental Disease, 187: 102-108.

Stubbs B, Firth J, Berry A, Schuch B F, Rosenbaum S, Gaughran F, Veronesse N, Williams J, Craig T., Yung R A, Vancampfort D, 2016. How much physical activity do people with schizophrenia engage in?: A systematic review, comparative meta-analysis and meta-regression. Schizophrenia Research, 176: 431-440.

Winkler R.C, 1971. The relevance of economic theory and technology to token reinforcement systems. Behaviour Research and Therapy, 9: 81-88.

Wolfe D.A, Mendes M.G, Factor D, 1984. A parent-administered program to reduce children's television viewing. Journal of Applied Behavior Analysis, 17: 267-272. 

be applied to their work. Under the terms of this license, no permission is required from the author(s) or publisher for members of the community to copy, distribute, transmit or adapt the article content, providing a proper, prominent and unambiguous attribution to the authors in a manner that makes clear that the materials are being reused under permission of a Creative Commons License. Views, opinions and conclusions expressed in this research article are views, opinions and conclusions of the author(s). Open Access Publishing Group and European Journal of Physical Education and Sport Science shall not be responsible or answerable for any loss, damage or liability caused in relation to/arising out of conflict of interests, copyright violations and inappropriate or inaccurate use of any kind content related or integrated on the research work. All the published works are meeting the Open Access Publishing requirements and can be freely accessed, shared, modified, distributed and used in educational, commercial and non-commercial purposes under a Creative Commons attribution 4.0 International License (CC BY 4.0). 